\title{
A CARNIBUS SE ABSTINEAT, NAM DURA EST CONDITIO NUTRIRE HOSTEM CONTRA QUEM DIMICES. LA ALIMENTACIÓN EN ALGUNAS REGLAS MONÂSTICAS HISPANAS DE LOS SIGLOS VI Y VII
}

\section{ANTONI RIERA I MELIS}

\author{
UDC: 27-788:641(365)"05/o6" \\ 27-42:641(365)"05/06" \\ Original scientific paper \\ Manuscript received: 02. 11. 2016. \\ Revised manuscript accepted: 07. 02. 2017. \\ DOI: 10.1484/J.HAM.5.113735
}

\author{
Universitat de Barcelona \\ Departement d'Història i Arqueologia \\ C. Montealegre, 8, Barcelona, o80o1 \\ Spain \\ antoniriera@ub.edu
}

In the sixth and seventh centuries, the Hispanic authors of monastic rules attached great attention to food. They designed a vegeratian diet, enough for the monk could perform their tasks and maintain their healt; with many fasting and few festive meals, because they considered that abundant and strong meals aroused passions. They used the privations of food as a moral corrective, to lead the ascetics by perfection's way.

Keywords: Leandro of Seville, Isidoro of Seville, Fructuoso de Braga, Benedict of Norcia, asceticism, monastic diet, vegetarianism, meat, fastings, hunger, moral correctives, continence, mortification.

\section{INTRODUCCIÓN}

Los ideólogos del ascetismo siempre han concedido una gran importancia a la alimentación. Según una teoría muy difundida entre los moralistas cristianos antiguos, la gula era el primero de los vicios y la castidad no se avenía con una dieta amplia, hipercalórica, fuerte. A principios del siglo V, Juan Casiano ya analizó con detalle, después de afirmar que sin continencia la vida cenobítica era inviable, la conexión causal existente entre los diversos pecados capitales; estableció, por primera vez, la secuencia que, empezando por la glotonería, conduce sucesivamente a la lujuria, la avaricia y la accidia ${ }^{1}$

Si la gula es la puerta de todos los vicios, el ayuno constituirá, pues, la primera de la virtudes monásticas. Si un régimen abundante aleja al asceta de la perfección, la sustracción de alimentos ha de ser una buena vía para corregir sus faltas y reencaminarle hacia la excelencia moral. Sólo mediante la renuncia a los placeres del gusto y del olfato puede el espíritu controlar los impulsos del cuerpo. Esta contribución al coloquio tiene como objetivos analizar tanto el sistema alimeticio contenido en las principales reglas monásticas hispanas de los siglos VI y VII, como el papel que asignaron a las restricciones nutricionales para mantener la disciplina interna y preservar el rigor ascético en la comunidad. A fin de poder captar con más precisión los aspectos genéricos y los rasgos específicos de estos códigos, se enmarcarán en su contexto económico, social y cultural, y se cotejará su contenido con el de la normativa redactada, unas décadas antes, por Benito de Nursia, que se expandiría, desde finales del siglo VIII, por todo Occidente, con el apoyo decidido de la administración carolingia.

\section{EL CONTEXTO ECONÓMICO, SOCIAL Y CULTURAL}

A mediados del siglo V se inició, a escala europea, un largo período de cambios estructurales que se prolongaría hasta 1030 aproximadamente. El hundimiento del Imperio Romano de Occidentey la instalación dentro de sus antiguas fronteras de diversos pueblos germánico propició un complejo fenómeno de integración de civilizaciones ${ }^{2}$. De esta síntesis surgirían una estrategia de explotación del medio ambiente, un paisaje, una organización de la economía, unas relaciones sociales y políticas, unos sistemas alimenticios y unas pautas culturales nuevas. A medida que se contraía la mano de obra esclava y se estancaba la tecnología agraria romana, los barbechos se alargaban, engendrando tupidos tapices arbustivos, cuya destrucción exigía la acción conjunta del fuego y el arado. En la gestión de las explotaciones, los criterios extensivos se imponían a los intensivos. El área cultivada se contraía lenta pero irreversiblemente, retrocediendo por doquier ante los prados, los setos y los bosques. El proceso, que se había iniciado en las áreas montañosas se extendió a poco a poco a las llanuras y los valles, donde la agricultura romana había alcanzado los rendimientos más altos.

La ganadería bravía, la caza, la pesca fluvial y la recolección, actividades pobres y marginales en la época romana,

${ }^{1}$ J. CASIANO, Colaciones, trad. L. y P. Sansegundo, 1, Madrid, 1998, p. 119-120; M. FOUCAULT, Le combat de la chasteté, Ph. Ariès y A. Bejin (dir.), Sexualités occidentales, Paris, 1982, p. 26-40; M. MONTANARI, Alimentazione e cultura nel Medievo, Roma-Bari, Laterza, 1988, p. 5, nota 10; G. ARCHETTI, I monaci a tavola: norme e consuetudini alimentari, in L. Pani Ermini (a cura di), Gli spazi della vita comunitaria, Atti del Convegno internazionale (Roma-Subiaco, 8-10 giugno 2015), Spoleto, 2016 (De re monastica, 5), pp. 305-327.

${ }^{2}$ Muy bien estudiado por M. MONTANARI, op. cit (n. 1), p. 12-22; ID., El hambre y la abundancia. Historia y cultura de la alimentación en Europa, Barcelona, 1993, p. 16-22; ID., Romains, barbares, chrétiens: à l'aube de la culture alimentaire européenne, en J.-L. Flandrin y M. Montanari (dir.), Histoire de l'alimentation, Paris, 1996, p. 279-282; ID., L'Occidente cristiano, en M. Montanari y F. Sabban (coord.), Atlante dell'alimentazione e della gastronomia, I, Turin, 2004, p. 130-144. 
se convirtieron, durante la Alta Edad Media, en trabajos corrientes, rentables económicamente y de creciente prestigio social. El medio natural, como consecuencia de la descomposición gradual de las estructuras romanas y la atenuación del impacto humano, devino más agreste³. Los rebaños estantes y trashumantes prosperaron por doquier, elevando la producción de carne y de queso ${ }^{4}$.

La progresión de los yermos y el auge de la ganadería coincidieron, además, con otros dos cambios importantes: el paso gradual de un sistema económico abierto, en el que una buena parte de la producción agropecuaria se orientaba hacia el mercado, a otro cerrado, caracterizado por el autoconsumo; y la sustitución del trigo, el cultivo principal de la agricultura romana, por la cebada, la escanda, la avena, el centeno, el mijo y el panizo ${ }^{5}$, cereales secundarios, menos exigentes en fertilizantesy más idóneos para la olla que para el horno. Las ciudades, al dismuir la afluencia de alimentos y materias primas, declinaron como centros manufactureros y comerciales, se ruralizaron, perdieron población; unos cambios que no tardaron en provocar una caída de la demanda local y una desarticulación del mercado interior. El comercio internacional, como consecuencia de la contracción gradual de la oferta y la demanda externas, decayó, se cerraron rutas y por las que continuaron abiertas circularon cargamentos cada vez más pequeños y homogéneos, integrados casi exclusivamente por alimentos estratégico cuya producción no se distribuía geográficamente de forma equilibrada, como la sal, y por productos de lujo de poco peso y alto valor, destinados a garantizar a las élites los gastos de prestigio con que manifestaban su rango. Durante la Alta Edad Media se produjo un descenso del nivel de consumo, más evidente entre las clases bajas que entre los poderosos, que, ante la mengua cuantitativa de la oferta de productos exóticos, procedieron a tesaurizar una parte creciente de sus excedentes monetarios Estas transformaciones no se produjeron, sin embargo, a un ritmo sincrónico a escala occidental; avanzaron tanto más rápidamente cuanto menos intenso había sido el proceso de romanización. El mercado interior, en los reinos "germánicos", se desarticuló gradualmente;

En Hispania, la evolución estructural y paisajística de la Alta Edad Media no rebasó, sin embargo, la fase inicial; quedó circunscrita cronológicamente a la época del reino visigodo de Toledo (507-711). La conquista musulmana integró, en la segunda década del siglo VIII, la mayor parte de la Península Ibérica al Islam; que impulsó, entre el Irán y el litoral atlántico lusitano, una renovación agraria, un reavance de las sementeras a expenas de los yermos. Los nuevos conquistadores expandieron por doquier los regadíos, aclimataron nuevos cultivos y pusieron en explotación los suelos que los romanos no habían roturado por improductivos $^{6}$; difundieron modelos de gestión intensivos, abiertos, orientados hacia el mercado. Los cristianos fugitivos de la invasión se refugiaron al norte del Duero y el Llobregat, en unas regiones de clima atlántico o mediterráneo de montaña, con una economía rural basada en la ganadería bravía. Los recién llegados, procedentes de llanuras de clima mediterráneo continental, se esforzaron por expandir el cultivo de los cereales y de la vid en estas tierras septentrionales, húmedas y frías, anteponiendo el autoconsumo a la productividad.

La economía rural del reino visigodo de Toledo constituye un tema poco estudiado, por la escasez y el laconismo de las fuentes escritas coetáneas: inscripciones sobre pizarras ${ }^{7}$, crónicas $^{8}$, códigos legislativos $^{9}$, actas conciliares ${ }^{10}$, reglas monásticas $^{11}$, biografias ${ }^{12} y$ textos científico ${ }^{13}$. Este déficit in-

\footnotetext{
${ }_{3}^{3}$ Como han demostrado V. FUMAGALLI, L’uomo e l'ambiente nel Medieovo, Roma-Bari, 1992, p. 4-7 Y 33-37; G. ORTALLI, Lupi, genti, culture. Uomo e ambiente nel medioevo, Turín, 1997, p. 3-57.

${ }^{4}$ A. RIERA i MELIS, La carn als models alimentaris monàstics dels segles VI i VII, en Història de la ramaderia i la veterinària als Països Catalans, Barcelona, 1999, p. 37-40; G. ARCHETTI, "Vas optimo lacte plenum". Latte e formaggio nel mondo monastico, in G. Archetti y A. Baronio (a cura di), La civiltà del latte. Fonti, simboli e prodotti dal Tardoantico al Novecento, Atti dell'incontro nazionale di studio (Brescia, 29-30 maggio 2008), Brescia, 2011 (Storia cultura e società, 3), p. 249-278.

${ }^{5}$ M. MONTANARI, L'alimentazione contadina nell'alto Medioevo, Nápoles, 1979, p. 109-150.

${ }^{6}$ Andrew M. Watson, hacia 1970, llegó a acuñar el término "revolución verde àrabe" (A. M WATSON, The Arab Agricultural Revolution and its diffusion, 700-110o, en The Journal of Economic History, XXXIV, 1, Cambridge, 1974, p. 8-35; ID., A medieval green revolution, en A. Udovich (ed.), The Islamic Middle East, 700-190o, Princeton, 1981, p. 29-58; ID., Agricultural Inovation in the Early-Islamic World. The Diffusion of Crops and Farming Techniques, 70o-1100, Cambridge, 1983. Sus propuestas, sin embargo, fueron cuestionadas immediamentepor otros expertos, que consideraron que atribuía a los árabes la difusión de cultivos que ya habían sido aclimatados, antes del siglo VIII, por los romanos y otros pueblos (J. JOHNS, A Green revolution?, en Journal of African History, 25, 1984, p. 343-344; C. CAEN, Review of Agricultural innovation in the Early Islamic World, by Andrew Watson, en Journal of the Social and Economic History of the Orient, 29, 2, 1986, p. 213-224; F. AUBAILE-SALLENAVE, L'agriculture musulmane aux premiers temps de la conquête: apports et emprunts, à propos du 'Agricultural innovation in the early Islamic world de A.M. Watson, en Journal d'Agriculture Traditionelle et de Botanique Appliquée, XXXI, 1984, p. 251-256). Recientemente Michael Decker, sin cuestionar la existencia de un legado agrario musulmán, ha reexaminado a la baja su alcance (M. DECKER, Plants and progress: Rethinking the Islamic Agricultural Revolution, en Journal of World History, XX, 2, 2009, p. 187-206).

7 Unas doscientas, localizadas en ambas vertientes del Sistema Central, entre las actuales provincias e Cáceres y Segovia, los expertos han fechado su redacción en los siglo VI y VIII, contienen contratos de compraventa, pagos de censos, listas de campesinos, cuentas y figuras. Han sido publicadas por M. GÓMEZ MORENO, Documentación goda en pizarra, Madrid, 1966; M.C. DÍAZ y DIAZ, Los documentos hispano-visigóticos sobre pizarra, en Studi medievalii, $3^{\text {a }}$ serie, VII, 1, 1966, p. 75-107; I. VELÁZQUEZ, Las pizarras visigodas (Entre el latín y su disgregación. La lengua hablada, siglo VI-VIII), Madrid, 2004. ${ }^{8}$ Editadas por K. Zeumer, in Monumenta Germaniae Historica (= MGH), Auctoris Antiquissimi, XI. Chronica minora II, Berlin, 1894, y J. GIL, Miscellania wisigothicae, Sevilla, 1972, p. 70-112.

${ }_{9}$ Código de Eurico, ed. A. d'Ors, Roma 196o; Lex Romana Visigotorum, ed. G. Haenel, 1ª reimpresión, Aalen 1962; Liber Iudiciorum ed. K. Zeumer, MGH, Leges, Sectio I, vol. 1, Hannover/Leipzig, 1880.

${ }^{10}$ Reunidas parcialmente y editadas por J. VIVES, Concilios visigóticos e hispano-romanos, Barcelona/Madrid, 1963.

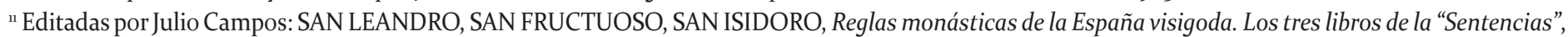
ed. J. Campos e I. Roca, Madrid, 1971, p. 7-211.

${ }^{12}$ BRAULIO DE ZARAGOZA, Vita Sancti Aemiliani, ed. L. Vázquez de Parga, Madrid, 1943; M.C. DÍAZ Y DÍAZ, Vida de San Fructuoso, Braga, 1974; Vitae Sanctorum patrun Emeritensium, ed. I. Velázquez, Madrid, 2008; ISIDORO DE SEVILLA, De viribus illustribus, ed. C. Codoñer, Salamanca, 1964; ILDEFONSO DE TOLEDO, De viribus illustribus, ed. C. Codoñer, Salmanca, 1972; R. COLLINS, The 'Autobiographical' work of Valerius of Bierzo: their Structure and purpose, en A. González Blanco (ed.), Los Visigodos: historia y civilización, Murcia, 1986, p. 425-442; M.C. DÍAZ y DÍAZ, Valerio del Bierzo, su persona y su obra, Léon, 2006.

${ }^{13}$ ISIDORO DE SEVILLA, Etymologiarum sive originum libri XX, ed. J. Oroz y M. Casquero, Madrid, 1982,
} 
formativo, sin embargo, está empezando a ser contrarrestado por las aportaciones de la arqueología. De de la información aportada por ambos tipos de fuentes parece desprenderse un declive general de las ciudades, de la manufactura urbana y del comercio exterior, una ruralización de la vida y la económia, una preponderancia de unas estructuras agropecuarias romanas degradas, de un paisaje más parecido al que había predominado en el Mediterráneo Occidental durante la Baja Antigüedad que al que se impondría en Occidente en la Alta Edad Media.

Algunas grandes explotaciones creadas en la época romana - como la villa La Coscosa (Badajoz) - continuaban en plena actividad en el siglo VII. Muchas más habían desapercido en la fase final del Bajo Imperio. Unas pocas habían surgido después de la instalación de los visigodos en la Penínula, como la de Gerticos (Salamanca). Monopolizaban su propiedad el Fisco, los miembros de la oligarquía germánica y las instituciones religiosas. Una población campesina, integrada por colonos, esclavos, libertos y encomendados, aseguraba su explotación ${ }^{14}$. A mediados del siglo VI, el rey Leovigildo entregó al abad Nancto ${ }^{15}$ un predio del Fisco público, en las inmediaciones de Mérida, con los siervos que lo cultivaban, para que viviera de las rentas generadas por el trabajo de estos ${ }^{16}$. La necesidad de contener el avance de los yermos explica la resistencia de los concilios generales y provinciales a autorizar la manumisisón total de los esclavos de la Iglesia, que reducía sustancialmente la productividad de sus patrimonios. Los censos anuales pagados por los colonos a los propietarios de la tierra debieron de ser en especie y su cuantía oscilaría en torno a una décima parte de la cosecha ${ }^{17}$.

Durante los siglo VI y VII, el legado agrario romano, por lo menos en la Tarraconense, la Bética y la Lusitania, experimentó sólo ligeros cambios, tanto en el patrón de cultivo como en las técnicas. En las dos submesetas castellanas continuaban cultivándose, en rotaciones bienales, trigo y cebada $^{18}$. La viña debía de seguir jugando un papel importante en los secanos mediterráneos ibéricos, puesto que fue objeto de protección específica por parte de los poderes públicos ${ }^{19}$. Entre los alimentos que Masona, obispo de Mérida, repartía periódicamente, hacia 590, entre los pobres de la ciudad y su término figuraba el vino ${ }^{20}$. Los habitantes del valle del
Segura, en 713, se comprometerían, a cambio de conservar sus propiedades y sus señales de identidad cultural, a entregar anualmente, per capita, a los musulmanes, entre otros alimentos, cuatro cántaros de mosto, cuatro de vinagre y dos de aceite ${ }^{21}$. Los legisladores visigodos, conscientes de su importancia económica, sancionaron la destrucción de un olivo con multa de cinco sólidos, de una cuantía superior a la establecida para los frutales, tasados en tres solidos cada uno $^{22}$. Masona, a finales del siglo VI, incluía el aceite en sus reiteradas distribuciones de alimentos a los necesitados de su diócesis ${ }^{23}$. La economía agraria del valle del Guadalquivir siguió girando en torno a los olivares. Isidoro de Sevilla ofrece una clasificación de los aceites que podría constituir un reflejo de la realidad coetánea y no una mera síntesis erudita de los tratados agronómicos clásicos (Etimologías, XVII, 7.68).

Bastantes de los regadíos creados durante le Bajo Imperio perduraron en los siglos VI y VII; la legislación visigoda procuró garantizar una gestión adecuada de los cursos fluviales, sancionando los hurtos de agua ${ }^{24}$. En algunas huertas se cultivaron frutales, que en el Liber Iudiciorum son designados con el término genérico de pomiferae, excepto la higuera, que aparece con su nombre específico ${ }^{25}$. Los vergeles (pomaria) debieron de estar integrados, como en la época romana, por manzanos, perales, ciruelos y membrillos ${ }^{26}$. Otros huertos se destinaron, en cambio, a la producción de verduras y legumbres. Tanto las unas como los otros estaban cercados, para protegerlos de las posibles incursiones de los animales extraviados y de los hurtos. La destrucción de hortalizas sólo estaba sancionada, sin embargo, con el pago de una pequeña compensación en metálico ${ }^{27}$.

La ganadería menor y mayor, articulada a la agricultura, no faltaría en ninguna de las regiones de la Península Ibérica. A mediados del siglo VI, el rey Leovigildo entregó - como ya se ha expuesto - al abad Nancto ${ }^{28}$ un predio en la Lusitania y un rebaño de ovejas ${ }^{29}$. Unas décadas después, las inscripciones en pizarra localizadas en el valle del Duero, una región esencialmente cerealista, documentan la existencia de pequeños rebaños de ovejas y cerdos en poder de las famílias campesinas, sujetos a sustracción anual por parte del propietario de la tierra, quien les cedía temporalmente una

\footnotetext{
${ }_{14}$ P.D. KING, Derecho y sociedad en el reino visigodo, Madrid, 1981, p. 183-214

${ }^{15}$ Que, procedente del Norte de África, se había refugiado en el reino visigodo.

${ }^{16}$ J. ORLANDIS, Historia Económica y Social de la España Visigoda, Madrid, 1975, p. 129.

${ }^{17}$ Una ley del Liber Iudiciorum (X.1.19) regula la entrega de viñas pro decimis. Las Fórmulas visigóticas establecen el mismo canón (fórmula XXXVI).

${ }^{18}$ Dos de las pizarras continenen distribuciones de estos dos tipos grano entre los agricultores para la siembra.

${ }^{19}$ La destrucción deliberada de una viña obligaba al culpable a indemnizar al propietario con la entrega de dos del mismo valor; el robo de vendimia debía ser restituido in duplo: Liber Iudiciorum, II, 1.2.

${ }^{20}$ Vitae Sanctorum patrum Emeritensium, ed. J.N. Garvin, Washington, 1946, p. 194.

${ }^{21}$ La capitulación, firmada por Abd al-Aziz y Teodomiro, un noble local, ha sido analizada por: J. GARCIA ANTÓN, Sobre los orígenes de Todmir, en Antigüedad y cristianismo, 2, 1985, p. 369-383; S. GUTIÉRREZ LLORET, La cora de Tudmir de la Antigüedad tardía al mundo islámico: poblamiento y cultura material, Madrid, 1996.

${ }^{22}$ Liber Iudiciorum VIII, 3.1.

${ }^{23}$ Véase supra, nota 20.

${ }^{24}$ Liber Iudiciorum, VII, 4.31.

${ }^{25}$ Liber Iudiciorum, VIII, 2.2.

${ }^{26}$ R.H. SMITH, Medieval agrarian society in its prime: Spain, en M.M. Postam (ed.), The Cambridge Economic History of Europe, 1, Cambridge, 1966, p. 441; P.D. KING, op. cit. (n. 14), p. 240.

${ }^{27}$ P.D. KING, op. cit. (n. 14), p. 240.

${ }^{28}$ Véase supra, nota 15.

${ }^{29}$ J. ORLANDIS, op. cit. (n. 16), p. 129.
} 
vaca para que pudieran roturar sus campos ${ }^{30}$. Los animales aparecen clasificados, por razón de su edad, en anniculi (de un año), sequanes (de año y medio) y trinos (de tres años), lo que evidencia un notable conocimiento de la cría de ganado ${ }^{31}$. En estos hatos de los agricultores no faltaban nunca los cerdos, su principal fuente de carne fresca, salazones y grasa de cocción. En algunas regiones, como la Lusitania, la ganadería porcina no quedó circunscrita, sin embargo, a las economías domésticas, se practicó a mayor escala. La magnitud y la importancia económica de las piaras ha quedado reflejada claramente en las normas que regulaban minuciosamente la explotación de los bosques de glandíferas. Los legisladores facultaron a los propietarios de encinares y robledos a exigir una décima parte de los animales que ingresaran en ellos durante la montanera, y una vigésima parte de los que continuaran en ellos después ${ }^{32}$.

Diversas leyes autorizaban a los viandantes a introducir sus animales en los barbechos privados y permanecer en ellos dos días, así como ramonear todo tipo de árboles, excepto los glandíferos ${ }^{33}$. Aunque los textos aluden específicamente a viajeros (iter agentibus) y a sus animales de carga, es probable que también se beneficiaran de estas concesiones los pastores trashumantes, que anualmente conducían sus rebaños desde las tierras bajas de los valles del Duero, Tajo y Ebro a los pastos de verano de las montañas circundantes, y viceversa $^{34}$. Otras normas del Liber Iudiciorum refuerzan la verosimilitud de esta hipótesis, al establecer que los animales extraviados continuaban perteneciendo a su dueño, obligar a quienes los hallaren a notificarlo a las autoridades locales y desautorizar al propietario a retener las reses que habían penetrado en sus tierras 35 .

Las hagiográfías y las reglas monásticas acreditan que la ganadería alcanzó su máximo desarrollo en algunas comarcas montañosas de Gallecia y en las estribaciones septentrionales del Sistema Ibérico, donde se convirtió en la base de la economía rural. El padre de Fructuosos de Braga, un duque visigodo poseía, hacia el año 6oo, un gran patrimonio en la comarca del Bierzo, cuya principal fuente de riqueza eran los rebaños ${ }^{36}$. Unas décadas más tarde, la ganadería lanar se había convertido también en la actividad económica fundamental de algunos monasterios galaicos; su dependencia de los hatos llegó a ser tan fuerte que los anónimos redactores de la "Regla Común" concedieron un estatuto especial a los monjes pastores, alegando que de su trabajo vivía toda la comunidad $^{37}$. El eremita Valerio del Bierzo, que vivió casi coetánemente en aquellos mismos parajes, recuerda en su autobiografía que entre las familias serviles de los grandes dominios abundaban los porquerizos ${ }^{3}$. San Millán, en su juventud, apacentó rebaños de ovejas en la Alta Rioja39.

El triunfo de un nuevo sistema de producción y de consumo, basado en una combinación equilibrada de las tareas agrarias y las actividades silvopastoriles, tuvo importantes consecuencias alimentarias. El consumo de carne, desde el siglo $\mathrm{V}$, se incrementó gradualmente en todo el Occidente, aunque a un ritmo diferente en cada uno de los estamentos sociales. El pan perdió la centralidad de que había gozado en los sistemas alimenticios populares romanos, se convirtió en un alimento más; el vacío generado por su retroceso fue ocupado por las gachas, las polentas y las sopas ${ }^{40}$.

Las transformaciones estructurales afectaron también a la cultura popular, la oratoria sacra, el funcionamiento interno de las comunidades monásticas y la medicina culta. El agricultor fue reemplazado por el pastor como paradigma social. A principios del siglo V, Pedro Crisólogo ya había presentado en sus homilías, al obispo como un buen pastor que protegía diligentemente al rebaño (los fieles) de todos los peligros y lo conducía con su voz (la predicación) a los mejores pastos y cargaba al cuello los corderos más débiles (los catecúmenos) para no perderlos ${ }^{41}$.

La medicina clásica había considerado el pan como el mejor comestible, puesto que contenía "más sustancia nutritiva que cualquier otra vianda” ${ }^{22}$. La carne, en cambio, había

\footnotetext{
${ }^{30}$ Notitia in qua ordenatu est quos ... consignemus Simplicio, id est: sesquanes [oves] cum agnus suus, det scrova una, vacca una hospitio Matratium, quum pariat in corte domini sui Valentini, vitulas duas, triticum modios XXV: cit. G. RIPOLLy I. VELÁZQUEZ, La Hispania visigoda. Del rey Ataúlfo a Don Rodrigo, Madrid, 1995, p. 15; L. GARCÍA MORENO, El paisaje rural y algunos problemas ganaderos en España durante la Antigüedad tardía (s. V-VIII), en Estudios en homenaje a Don Claudio Sánchez Albornoz, Buenos Aires, 1983, p. 401-412.

${ }^{31}$ J. ORLANDIS, op. cit. (n. 16), p. 129.

${ }^{32}$ Liber Iudiciorum, VIII, 5.1-4.

${ }_{33}$ Liber Iudiciorum, VIII, 3.9; VIII, 4.27.

34 P.D. KING, op. cit. (n. 14), p. 226.

${ }^{35}$ Liber Iudiciorum, VIII, 4.11 y 14; VIII, 5. 6-8

${ }^{36} \mathrm{~J}$. ORLANDIS, op. cit. (n. 16), p. 130.

${ }_{37}$ Isti non debent despicere quas delegatas oues habent; quia exinde, non unam, sed multas consecuntur mercedes: inde sustentantur infirmi, inde recreantur paruuli, inde fouentur senes, inde redimuntur captiui, inde suscipiuntur hospites et peregrini, et insuper uix tribus mensibus per pleraque monasteria abundarentur, si sola cotidiana fuissent paxamacia in hac provincia plus omnibus terris laboriosa: Regla Común, en SAN LEANDRO, SAN FRUCTUOSO, SAN ISIDORO, op. cit. (n. 11), p. 187-188.

${ }^{38}$ R. COLLINS, op. cit. (n. 12), p. 425-442.

39 J. ORLANDIS, op. cit. (n. 16), p. 129.

${ }^{40}$ R.S. LOPEZ, La révolution commerciales dans l'Europe médiévale, París, 1974, p. 6o; P. BONNASSIE, La Catalogne du milieux du Xe siècle a la fin du XI siècle. Croissance et mutations d'une société, I, Tolosa, 1975, p. 95; M. MONTANARI, op. cit. (n. 5), p. 405-406, 451-455 y 464-468; ID., op. cit. (n. 1), p. 17; ID., L'Occidente cristiano, op. cit. (n. 2), p. 138-139; A. RIERA i MELIS, Sistemes alimentaris i estructura social a la Catalunya de l'alta edad mitjana, en Alimentació $i$ societat a la Catalunya medieval, Barcelona, 1988, p. $21-22$ y 24.

${ }^{41}$ Pastor bonus peruigiles noctes, dies anxios ducit, ... ne quid noxium moliantur... Non est ouium vox ista, pastoris est; sed dulci iubilo et uaria modulatione aut gregem producit ad pascuam, aut sub nemore umbroso fessum pecus continet et quietem ... Ubi uernalis aurae tempus, ubi agni ouium partus aperire, ubi per campos, prata, uias coeperint fecundae greges germina copiosa dispergere, pastor bonus seponit epulas et cantos, et discursu anxio teneros quaerit, legit, colligit fetus, atque eos collo, humeris, ulnis laetor uector imponit, aut saluos omnes perferat, ut tutas perducat ad caulas: A. OLIVAR, La vida rural i la pastoral reflectides en la predicació de Pere Crisòleg, en Spania. Estudis d'Antiguitat Tardana oferts en homenatge al professor Pere de Palol i Salellas, Barcelona, 1996, p. 180-181.

${ }_{42}$ CELSO, De medicina, II, 18; M. MONTANARI, El hambre y la abundancia, op. cit. (n. 2), p. 24, nota 34.
} 
suscitado bastantes recelos, se la había considerado como un alimento que se debía consumir con moderación. Durante el siglo V, la valoración dietética de estos dos alimentos, sin embargo, se invirtió. Los médicos empezaron a cuestionar el protagonismo que el pan había tenido hasta entonces en las mesas occidentales, incluidas las mediterráneas ${ }^{43}$; tendieron a despojarlo de su condición de símbolo de civilización. Esta caída del prestigio del pan coincidió con un ascenso del de la carne, que se convirtió en el valor alimenticio por excelencia. ${ }^{44}$.

Anthimo, hacia el 520, ya refleja claramente, en su De observatione ciborum ${ }^{45}$, la revalorización dietética, gastronómica y simbólica experimentada por la carne. Este médico italiano, de origen y formación griegos, concede, en su epístola dirigida al rey franco Teodorico I, una atención preferente a los comestibles de origen animal y describe sus propiedades nutritivas. Especifica la mejor manera de cocinar una vasta gama de mollas, desde las de cerdo, oveja, cordero, cabrito, vaca y buey, hasta las de faisán, perdiz, palomo, pavo real y oca, pasando por las de ciervo, rebeco, jabalí y liebre ${ }^{46}$. Eleva el lardo de cerdo a la categoría de grasa de cocción preferente alaba el sabor que confiere a toda suerte de platos ${ }^{47}$.

En la cocina de los estamentos privilegiados, desde principios del siglo VI, se manipulaban cotidianamente, pues, carnes de gustos, texturas y procedencia muy diversos. La ganadería y la caza aseguraban a los poderosos un abastecimiento fluido y variado de proteínas y grasas. El texto De observatione ciborum demuestra, además, que la carne aparecía en la mesa asada, al horno, guisada, hervida, frita o cruda ${ }^{48}$. Su autor sólo recomendaba restringir el consumo de carne cruda, al considerarla de digestión más prolongada que la cocida ${ }^{49}$. El aceite de oliva, tan apreciado entre los romanos de toda condición social ${ }^{50}$, se ha convertido en un ingrediente para las cocinas de los pobres $^{51}$ y de los ascetas ${ }^{52}$; en las de los magnates, se utizaban como grasas de cocción casi exclusivamente el lardo o el tocino. La ausencia de inventarios post obitum y de receptarios no permiten, sin embargo, conocer con detalle el instrumental y los conocimientos técnicos utilizados por los cocineros para potenciar las propiedades organolépticas de los diversos tipos de carne. Se suele considerar que el atractivo de un plato, incluso en los comedores reales de Toledo, Rávena, Metz, Soissons, París o Orleans dependía más de la cantidad de molla que contenía que de la complejidad de su elaboración y de la estética de su presentación; la mayoría de los expertos sostienen que incluso los comensales privilegiados se regían entonces por un criterio más cuantitativo que cualitativo. La escasa referencias aportadas por las fuentes escritas coetáneas acreditan que los asados de caza mayor y de volátiles ocupaban el primer lugar entre sus preferencias gastronómicas. Los magnates se debieron de contentar entonces con una cocina técnicamente sencilla, basada en cocciones prolongadas, capaz de molificar y potenciar el sabor todo tipo de carnes.

Los campesinos, siguiendo el ejemplo de los poderosos, también consideraban la carne como el alimento más placentero y sano, como una fuente de salud y de fuerza física ${ }^{53}$. Por otra parte, el avance de los yermos permitía por doquier a las familias rurales no sólo criar cerdos, ovejas, cabras, gallinas y ocas ${ }^{54}$, sino también capturar jabalíes, conejos, liebres, perdices, palomos y otros volátiles ${ }^{55}$. Pocas veces en la historia la ganadería y la caza menores habían estado tan al alcance de las famílias rurales, que pudieron integrar pequeñas cantidades de carne fresca, salazones y queso a sus comidas cotidianas. Esta variedad de los ingredientes, además de constituir una garantía desde el punto de vista del equilibrio biológico, significaba también un amplio margen de seguridad en los momentos de crisis productiva. Cuanto más numerosos eran los productos a disposición de los labriegos, menor era el peligro de que padecieran hambre ${ }^{56}$. El régimen alimentario de los campesinos se caracterizó por la precaridad cuantitativa, la variedad de los componentes y

\footnotetext{
${ }_{43}$ M. MONTANARI, El hambre y la abundancia, op. cit. (n. 2), p. 25.

${ }^{44}$ M. MONTANARI, op. cit. (n. 1), p. 24-25 y 47.

${ }^{45}$ Un texto que por su originalidad ha atraído el interés de los historiadores de la medicina, como se desprende de sus numerosas ediciones: ANTHIMO, De Observatione ciborum, ed. V. Rose, Leipzig, 1877; ID., De Observatione ciborum, ed. S. H. Webern, Leyden, 1924; ID., De Observatione ciborum, ed. E. Liechtenhan, Leipzig, 1928; ID., De Observatione ciborum, ed. A. Marsili, Pisa, 1959; ID., De observatione ciborum, ed. J. Koldova, en Neznámé(?) regimen sanitatis vodnanského rukopiso c. 5, Brno, 2012, p. 40-50. De la carta d'Anthimo disponemos también de algunas traducciones al italiano (G. GENTILLI, Il medico bizantino Anthimo (VI secolo) e la sua epistola "De observatione ciborum, en Atti del XVI Convegno Nazionale della Società Italiana di Storia della Medicina, Bologna-Ravenna, 1959, p. 212-233; Andrea Marsili incluye otra al final de su edición, p. 37-137) y al inglés (M. GRANT, Anthimus. On the Observance of Foods, Blackawton, 1996). Este breve pero interesante tratado dietético ha sido analizado por M. MONTANARI, op. cit. (n. 1), p. 206-208; ID., El hambre y la abundancia, op. cit. (n. 2), p. 24-25; y por A. RIERA i MELIS, La carn als models alimentaris monàstics dels segles VI $i$ VII, en Història de la ramaderia i la veterinària als Països Catalans, Barcelona, 1999, p. 40-42. En adelante utilizaré siempre la edición de Julie Koldova.

${ }^{46}$ ANTHIMO, ed. J. Koldova, op. cit. (n. 45), p. 41-45; M. MONTANARI, op. cit. (n. 1) p. 207; ID., El hambre y la abundancia, op. cit. (n. 2), p. 24-25; A. RIERA i MELIS, op. cit. (n. 45), p. 41.

${ }^{47}$ A cuyas virtudes dietéticas y gastronómicas dedica un capítulo entero, el decimotecero: ANTHIMO, ed. J. Koldova, op. cit. (n. 45), p. $40-41$.

${ }^{8}$ Ibidem, p. 41-45.

${ }^{49}$ Prima sanitas ex cibis bene coctis et bene digestis constat ... nam, si necessitas exierit carnes uel alia crudiora manducare, non ad nimietatem, sed parcius: Ibidem, p. 40.

${ }^{50}$ Como lo demuestra el único - y tardío - receptario que nos ha llegado: APICIO, L'Art de la cuina, ed. y trad. J. Gómez i Pallarès, Barcelona, 199o, p. 43, $47,54,82,83,84,88,89,95,99,109,113$ i 128.

${ }^{51}$ Véase supra, nota 20.

${ }^{52}$ Véase infra, notas 100 y 101. G. ARCHETTI, "Infundit vinum et oleum". Olio e vino nella tradizione monastica, in Olio e vino nell'alto medioevo, Atti del convegno (Spoleto, 20-26 aprile 2006), Spoleto, 2007 (Settimane di studio della Fondazione Centro italiano di studi sull'alto medioevo, LIV), pp. 1099-1209.

53 M. MONTANARI, L'alimentazione contadina, op. cit. (n. 5), p. 451-468.

${ }^{54}$ Ibidem, p. 232-253.

55 Ibidem, p. 268-270 y $274-275$.

${ }^{56}$ M. MONTANARI, Mutamenti economico-sociali e trasformazioni dei regime alimentare dei ceti rurali, en ID., Campagne medievali. Strutture produttive, rapporti di lavoro, sistemi alimentari, Turín, 1984, p. 151.
} 
la monotonía de los menús, que - como ya se ha expuesto giraban sistemáticamente en torno a las gachas de cereales secundarios y los potajes de legumbres ${ }^{57}$.

\section{LAS PROPUESTAS ALIMENTARIAS MONÁSTICAS}

El bloque de adeptos a la carne, desde la Baja Antigüedad, coexistió, sin embargo, con otro colectivo, siempre minoritario, que reivindicó, por razones morales más que económicas o sanitarias, una dieta reducida, frugal, exenta de carne, y defendió las restricciones alimenticias periódicas. La vanguardia de este frente anticárnico estaba integrada por los representantes más cualificados del monacato; quienes, fieles a la herencia estoica e interesados por la excelencia ascética, defendían un comportamiento alimenticio antitético al desarrollado por los milites, que anteponía la anorexia a la bulimia, y consideraba el ayuno y la abstinencia como dos valores excelsos no sólo para los ascetas, sino para el conjunto de la sociedad secular.

El monacato experimentó un avance importante en los reinos "germánicos"; reforzó las distinciones entre el anacoretismo y el cenobitismo, y entre éste y el clero secular. Para evitar los riesgos de desviaciones morales y dogmáticas, el concilio ecuménico de Calcedonia (451) confió al control de los obispos los monasterios, que se convirtieron en polos de difusión espiritual y cultural, y en núcleos de producción agropecuaria con una fuerte capacidad de distribución. Los monarcas solían conceder una gran importancia a los cenobios, utilizándolos como agentes de dinamización económica y como contrapeso al poder creciente de la nueva aristocracia terrateniente.

En Italia, destacaron los monasterios de San Juan y San Pablo, San Esteban y Letrán, en Roma, Vivarium, en Calabria, Montecasino y Farfa, en el Lacio. En la Galia florecieron los monasterios de Marmoutier, cerca de Tours, Ligugé, en el Poitou, Lerins, en la isla de San Honorato, San Cosme y San Damián, en Auxerre, San Salvador, en Marsella, Fontenelle y Jumièges, en Normandía, y los femeninos de Santa Cruz, en Poitiers, y Celle, en Brignoles. Los primeros monasterios hispanos documentados son los de Asán, en Huesca, Dumio, en Gallecia, Bíclaro, de localización todavía no establecida, Gauliana, junto a Mérida, Servitano, en la Alcarria conquense, Agaliense, cerca de Toledo, y Honoriense, junto a Sevilla. Otra área en la que el monacato arraigó con fuerza fue Irlanda, como lo atestiguan los cenobios de Armagh, Ossory y sobre todo Bangor, de donde salió san Columbano para fundar los monasterios de Iona, en Escocia, Luxeil, en Borgoña, y Bobbio, cerca de Piacenza. Posteriormente sendas comunidades de monjes irlandeses se establercieron San Galo, en el cantón suizo del mismo nombre, y Fulda, en Hesse. A mediados del siglo VII, el movimiento benedictino desembarcaría en Inglaterra, donde crearía los monasterios de Jarrow y Wearmouth, en Northumbria.

Hasta finales del siglo VIII, cuando la administración carolingia impuso la uniformidad benedictina entre el Elba y el Llobregat, cada monasterio se había regido sucesivamente por normativas específicas, constituidas por la combinación de elementos extraídos de algunas reglas preexistentes. Los diversos códigos monásticos seleccionados por cada comunidad solían conservarse en un único manuscrito, el Codex regularum, que se convertía en la fuente de inspiración de sus sucesivos abades. A pesar de que los preceptos recogidos contuviesen disposiciones incompatibles, el guía espiritual correspondiente seleccionaba, en cada caso, un conjunto de principios mínimamente concordantes, con los que construía una normativa provisional, designada a menudo con el término de regula mixta ${ }^{5}$. En los escritorios monásticos de los reinos "germánicos", no solían faltar las reglas orientales de Pacomio y Basilio de Cesarea, y las occidentales de Jerónimo, Agustín de Hipona, Juan Casiano, Cesáreo de Arlés, Columbano de Bangor, del Maestro y de Benito de Nursia. Esta última norma ${ }^{59}$, redactada en torno a 550, para los monjes de Montecasino ${ }^{60}$, gozaría pronto, por su ponderación y funcionalidad, de gran aceptación y se extendería gradualmente por el Occidente, donde se convertiría en ampliamente mayoritaria antes del 800 .

En Hispania, durante el siglo VII, las órdenes masculinas se inspiraban preferentemente, en cambio, en la normas de Juan de Bíclaro, actualmente perdida, Isidoro de Sevilla, Fructuoso de Braga y la Regla Común, redactada por una asamblea de abades galaicos ${ }^{61}$. Las comunidades femeninas, por lo menos las ubicadas al sur del Guadiana, se guiaban sobre todo por el Libro de la educación de las vírgenes y del desprecio del mundo de Leandro de Sevilla ${ }^{62}$, algo más antiguo que las tres compilaciones anteriores, puesto que su redacción se ha situado hacia el 580. Este particularismo monástico ibérico ${ }^{63}$ no implicaba, sin embargo diferencias importantes acerca de las excelencias morales atribuidas a la frugalidad, a las renuncias alimentarias, como se desprende de los capítulos dedicados a regular la comida y la bebida de los monjes ${ }^{64}$.

Para diseñar la dieta de los ascetas, los redactores de las reglas se basaban en las teorías dietéticas clásicas. Todos ellos poseían un notable conocimiento de la medicina antigua,

\footnotetext{
57 Véase supra, nota 40.

${ }^{58}$ A. MUNDÓ, Il monachesimo nella peninsola Iberica fino al secolo VII. Questioni ideologiche eletterarie, en Il monachesimo nell'Alto Medieovo e la formazione de la civiltà occidentale, Spoleto, 1957, p. 95-97; A. LINAGE, Los orígenes del monacato benedictino en la Península Ibérica, I, León, 1973, p. 99-100.

${ }^{59}$ La Regla de San Benito, ed. G.M. Colombás y I. Aranguren, Madrid, 1979.

${ }^{60} \mathrm{G}$. TURBESSI, La Regola di S. Benedetto nel contesto delle antiche regole monastiche, en Erster Internationaler Regula Benedicti-Kongress, Hildesheim, p. 57-90; A. de VOGUÉ, Saint Benoît en son temps: regles italiennes et regles provençales au VIe siècle, en Ibidem, p. 169-193; ID., Autour de saint Benoît. La Règle en son temps et dans le nôtre, Bellefontaine, 1975; J. LECLERCQ, Autour de la Règle de saint Benoît, en Collectanea Cisterciensia, 37, Scourmont, 1975, p. 167-204.

${ }^{61}$ Editadas por Julio Campos: véase supra nota 37.

${ }^{62}$ Editada tambiénpor Julio Campos: véase supra, nota 11.

${ }^{63}$ Bien analizado por Antonio Linage (A. LINAGE, El ideal monástico de los padres visigóticos, en Ligarzas, I, València, 1968, p. 79-97; ID., La condición social y el régimen de trabajo en el monacato visigodo, en Ligarzas, 2 (1970), p. 5-19; ID., op. cit. (n. 58), I, p. 211-291) y por Julio Campos (J. CAMPOS, Lengua e ideas del monacato visigodo, en Anales Toledanos, III, Toledo, 1971, p. 219-234).

${ }^{64}$ La Regla de San Benito, op. cit. (n. 59), p. 82 y 135-139, SAN LEANDRO, op. cit. (n. 11), p. 56; SAN ISIDORO, op. cit. (n. 11), p. 93-94, 105; SAN FRUCTUOSO, op. cit. (n. 11), p. 147 i 158; Regla Común, op. cit. (n. 37), p. 180.
} 
que concedía una gran importancia a la alimentación. Para los seguidores del corpus hipocrático, la dieta constituía el principal instrumento tanto para evitar y curar la enfermedad, como para desarrollar cualquier estilo específico de vida, puesto que la salud consistía en el equilibrio de los cuatro humores (sangre, flema, bilis amarilla y bilis negra) ${ }^{65}$. Estas teorías médicas eran moduladas, sin embargo, por las enseñanzas bíblicas y patrísticas. Desde la expulsión de Adán y Eva del Paraíso Terrenal, los hombres habían tenido que "ganar el pan con el sudor de su frente"66, lo que les había obligado, según Basilio de Cesarea, a desarrollar la agricultura, la ganadería, el arte de la cocina y la ciencia de la medicina, "a fin de remediar las dolorosas consecuencias de aquella maldición" ${ }^{67}$.

El obispo de Cesarea defiende que, bajo el funcionamiento de la naturaleza, subyace un diseño providencial; ninguna hierba comestible surge de la tierra espontáneamente y sin una finalidad precisa, "sino para nuestro beneficio, por voluntad del Creador”. El monje puede utilizar, pues, "la raíces, las flores, los frutos" como alimentos; sólo debe excluir de su dieta los superfluos, cuya preparación "exige mucho tiempo", y los que contribuyen al deleite "de la carne" 68 . El hecho que algunas personas abusen de la comida y utilicen el arte culinario como fuente de placer no constituye un motivo suficiente para rechazar las ventajas dietéticas de un correcto uso de las viandas y de sus propiedades, utilizándolas siempre, sin embargo, en su justa medida, evitando los excesos ${ }^{69}$. Isidoro de Sevilla sostiene que el monje debe comer con mesura, nunca hasta el hartargo, "para que no se ahogue el espíritu"7o.

No existen, pues, alimentos prohibidos o contrarios a la ascesis claustral y a la vida cristiana en general, ni manjares intrínsecamentge malos; el juicio moral, en cada caso, depende del uso adecuado o impropio que se haga de ellos. La renuncia de un comestible sólo tiene sentido si permite una más rápida e intensa aproximación a Dios. El ayuno es un medio que adquiere un significado positivo o negativo según el uso que se haga de él. La carne es excluida de la dieta de los monjes sanos en casi todas las reglas orientales y occidentales $^{71}$. No aparece tampoco en la lista de alimentos adecuados para la vida contemplativa que Jerónimo, Sulpicio Severo y Paulino de Nola incluyeron en sus respectivas correspondencias. La Regla del Maestro autorizó, sin embargo, la aparición de la carne de aves en el refectorio entre Navidad y la Epifanía y desde Pascua hasta Pentecostés ${ }^{72}$. Benito de Nursia, prohibió explícitamente el consumo de carne de cuadrúpedos a los monjes sanos ${ }^{73}$. El padre del monacato occidental dejó sin precisar, no obstante, si los ascetas podrían consumir carne de bípedos en las grandes festividades del calendario litúrgico. Solución de compromiso - disimétrico - entre la exclusión total y la inclusión sin restricciones de la carne en las dietas de los monjes; propuesta deliberadamente ambigua, que significaba una invitación tácita a la renuncia total a la carne de mamíferos, con un margen de tolencia considerable, sin embargo, para la de aves. Leandro de Sevilla aconsejaba a su hermana, la abadesa Florentina, que prohibiera el consumo de todo tipo de carne a las monjas sanas de su comunidad, puesto que era una opción pésima alimentar conscientemente al propio enemigo $^{74}$. Isidoro de Sevilla, que conocía el código de su hermano y compartía sus ideas ascéticas, asignó, en su regla, a los monjes un régimen alimenticio equilibrado y suficiente, vegetariano. La carne, según Fructuoso de Braga, no era un alimento peligroso, vil o impuro, puesto que había sido creada por Dios, sino poco adecuado para los ascetas; su renuncia sistemática favorecía la vida contemplativa. El abad galaico, en su regla, la excluyó completamente de las dietas ordinarias y castigó severamente, con seis meses de reclusión, la ruptura de este veto ${ }^{75}$; autorizó, en cambio, el consumo de carne de aves durante los viajes prolongados, para que los monjes pudieran recuperarse físicamente de las largas caminatas ${ }^{7}$. Renunciar a los efectos saludables derivados de las propiedades nutricionales de los alimentos era un signo de obtinación; aceptar voluntariamente el don de la curación que aquellos proporcionan constituía, en cambio, un reconocimiento de la generosidad de Dios ${ }^{77}$. Todos los autores de reglas, conscientes de que la carne constituía un remedio muy eficaz contra la enfermedad, permitieron su inclusión en los platos destinados a la enfermería ${ }^{78}$.

Sólo a la luz de estas teorías médicas y enseñanzas bíblico-patrísticas adquieren sentido las normativas claustrales sobre la alimentanción, cuya principal finalidad consistía en complacer a Dios, en alcanzar la excelencia moral. Mientras que los regímenes alimentarios benedictino e irlandés se

\footnotetext{
${ }_{55}$ Para una visión amplia de estos conceptos véase: M. NICOUD, Les régimes de santé au Moyen Age. Naissance et diffusion d'une écriture medical, Roma, 2007; F. PUCCI DONATI, Dieta, salute, calendari. Dal regime stagionale antico ai regimina mensium medievali: origine di un genere nella letteratura medica occidentale, Spoleto, 2007.

${ }^{66}$ Génesis 3, 23.

${ }^{67}$ BASILIO DE CESAREA, Le regole. Regulae fusius tractate-Regulae brevius tractate, ed. L. Cremeaschi, Magnano, 1993, p. 211; G. ARCHETTI, 'Mensura victus constituere'. Il cibo dei monaci tra Oriente et Occidente, en L'alimentazione nell'Alto Medioevo: pratiche, simboli, idoelogie, 2, Spoleto, 2016 (LXIII Settimane di Studio), p. 760 .

${ }^{68}$ BASILIO DE CESAREA, op. cit. (n. 67), p. 207; G. ARCHETTI, op. cit. (n. 67), p. 760.

${ }^{69}$ BASILIO DE CESAREA, op. cit. (n. 67), p. 208; G. ARCHETTI, op. cit. (n. 67), p. 760-761.

${ }^{70}$ Non erit usque ad satietatem reficiendum corpus, ne forte intereat animus: SAN ISIDORO, op. cit. (n. 11), p. 105.

${ }^{71}$ He examinado con detenimiento el papel asignado a la carne en las alimentaciones monásticas occidentales de la Postanigüedad en A. RIERA i MELIS, op. cit. (n. 4), 1999, p. 35-74.

${ }^{72}$ Regla del Maestro, 53.30-31; G. ARCHETTI, op. cit. (n. 67), p. 775.

${ }_{73}$ Carnium vero quadrupedum omnimodo ab omnibus abstineatur comestio,praeter omnino debiles ergrotos: La Regla de San Benito, op. cit. (n. 59), p. 136.

${ }^{74}$ Cui tamen suppetit uirtus, a carnibus se abstineat; nam dura est conditio nutrire hostem contra quem dimices: SAN LEANDRO, op. cit. (n. 11), p. 65.

${ }^{75}$ SAN FRUCTUOSO, op. cit. (n. 11), p. 142.

${ }^{76}$ Ibidem.

77 G. ARCHETTI, op. cit. (n. 67), p. 761.

${ }^{78}$ Véase supra, notas 67 y 71.
} 
expandían - como ya se ha expuesto - al sur y al norte de los Alpes, respectivamente; en la Península Ibérica, Leandro de Sevilla, Isidoro de Sevilla, Fructuoso de Braga y los anómino autores de la Regla Común redactaban sus propuestas dietéticas basándose en unos conocimientos médicos y morales muy parecidos a los del fundador del benedictinismo, de ahí que llegaran a resultados parecidos. Es posible incluso que alguno de ellos, especialmente Isidoro de Sevilla, tuviera en su escritorio un ejemplar de la norma italiana a la hora de redactar la suya ${ }^{79}$.

\subsection{La dieta ordinaria}

Los monjes efectuaban normalmente dos comidas al día, a la hora sexta y a vísperas ${ }^{80}$. La observancia de este horario, calculado en función de la luz diurna, era preceptiva y su quebranto injustificado implicaba un correctivo ${ }^{81}$. Sólo la llegada imprevista al monasterio de viajeros o eclesiásticos, con los que el abad o la comunidad, en señal de cortesía, compartían los alimentos, podía alterar eventualmente esta rigidez horaria ${ }^{82}$. Fuera de las horas convenidas, los ascetas no podían comer ni beber nada ${ }^{8}$.

La dieta cotidiana se componía, en la mayoría de cenobios, de dos platos calientes, de hortalizas y legumbres cocidas, y de un tercer plato frío, de fruta o de verduras tiernas crudas, en aquellas épocas en que la comunidad disponía de estos alimentos ${ }^{84}$. La sal, el vinagre y el aceite potenciaban sistemáticamente el sabor de los potajes, menestras y ensaladas ${ }^{85}$. Una porción de pan, de calidad y magnitud no especificada $^{86}$, acompañaba sistemáticamente los platos calientes y fríos. La bebida consistía en una medida de vino, que oscilaba entre los tres vasos de Isidoro de Sevilla y el cuarto de sextarius de Fructuoso de Braga $^{87}$. En las áreas alejadas del Mediterráneo, donde la productividad de la viña descendía considerablemente, el vino podía ser substituido por la sidra, una bebida mucho más asequible en las regiones de clima atlántico, como la Gallecia ${ }^{88}$. En la primera mitad del siglo VII, el régimen alimentario de los monjes hispanos coincidía casi exactamente con el instaurado por Benito de Nursia, unos cincuenta años antes, en Montecasino ${ }^{89}$.

La cena, cuando se efectuaba, debía de ser bastante más ligera que el almuerzo, ninguna de las cuatro normas hispanas especifica su composición. La Regla del Maestro, más explícita al respecto, establece que los monjes, a vísperas, recibirán un tercio de la ración del pan, un plato crudo y fruta $^{90}$. La Regla de Montecasino establece sólo que el mayordomo, durante los meses en que la comunidad realice dos comidas al día, ha de reservar para la noche una tercera parte de la ración de pan ${ }^{91}$. Es probable que consistiera en el plato "crudo" y en unas porciones de pan y de vino sustraídas del almuerzo. De ser así - y el testimonio de alguno de los primeros exégetas del código, como Hildemaro, parecen confirmarlo -, la segunda colación no implicaría un incremento cuantitativo sino una distribución horaria diferente de la dieta monástica92.

\subsection{Los regímenes especiales}

Las restricciones alimenticias, según los autores de reglas monásticas, sirven para purificar el corazón, para alcanzar

\footnotetext{
${ }_{79}$ R. SUSÍN ALCUBIERRE, Sobre las fuentes de la 'Regula Isidori', en Salamanticensis, 14/2, Salamanca, 1967, p. 371-394.

${ }^{80}$ In refectione monachorum, a diebus Pentecostem usque ad autumni principium, tota aestas, interdiana prandia inuitet; reliquum tempus suspendat prandia; cena tantum adponatur (SAN ISIDORO, op. cit. (n. 11), p. 106). En la Regla de Compludo no aparece ninguna referencia a la cena pero, cuando establece el horario del trabajo manual de los monjes, especifica que la comunidad, durante la primavera y el verano, almorzará a sexta (SAN FRUCTUOSO, op. cit. (n. 11), p. 143-144). De la larga duración del día en estos meses y del ejemplo de la mayoría de normas monásticas ocidentales anteriores y coetáneas parece desprenderse que los monjes galaicos, entre la Pascua y el equinoccio de otoño, se volverían a reunir en el refectorio, excepto en la jornadas penitenciales, al atardecer, para cenar. Cf. G. ARCHETTI, "Nihil operi Dei praeponatur”. Il tempo dei monaci nel Medioevo, in G. Archetti y A. Baronio (a cura di), “Tempus mundi umbra aevi". Tempo e cultura del tempo tra Medioevo e età moderna, Atti dell'incontro nazionale di studio (Brescia, 29-30 marzo 2007), Brescia, 2008 (Storia, cultura e società, 1), p. 51-80.

${ }^{81}$ Véase infra, notas 129-131.

${ }^{82}$ SAN FRUCTUOSO, op. cit. (n. 11), p. 157.

${ }^{8}$ SAN ISIDORO, op. cit. (n. 11), p. 106 y 116; SAN FRUCTUOSO, op. cit. (n. 11), p. 143, 147 y 153.

${ }^{84}$ Refectio mensae tribus erit pulmentis; olerum scilicet et leguminum; et si quid tertium fuerit idem pomorum (SAN ISIDORO, op. cit. (n. 11), p. 106). Vivant [monachi] enim solis oleribus et leguminibus (SAN FRUCTUOSO, op. cit. (n. 11), p. 142). Cf. G. ARCHETTI, "Parvula poma sumebat". Suggestioni dal mondo monastico, in I. Naso (a cura di), Le parole della frutta. Storia, saperi, immagini tra medioevo ed età contemporanea, Torino, 2012 (Centro studi per la storia dell'alimentazione e della cultura materiale "Anna Maria Nada Patrone"), p. 67-89.

${ }^{85}$ Véase infra, notas 100-101.

${ }^{86}$ Ninguna de las cuatro reglas hispánicas analizadas especifica el peso de la ración diaria de pan; se puede suponer, sin embargo, que en los cenobios de la Bética, zona muy romanizada y con una larga tradición en el cultivo de los cereales, no se alejaría mucho del previsto por Benito de Nursia, una libra. Más difícil lo tenían las comunidades galaicas, puesto que las condiciones edáficas y climáticas comprometían - como ya se ha expuesto - su abastecimiento frumentario; en sus refectorios se debieron de consumir, por lo menos transitoriamente, panes más pequeños y oscuros que los recomendados por los maestros de ascetismo mediterráneos: Regla Común, op. cit. (n. 37), p. 188. Cf. G. ARCHETTI, "Noli pane satiari". Il pane sulla mensa dei monaci, in G. Archetti (a cura di), La civiltà del pane. Storia, tecniche e simboli dal Mediterraneo all'Atlantico, Atti del Convegno internazionale di studio (Brescia, 1-6 dicembre 2014), Spoleto, 2015 (Centro studi longobardi. Ricerche, 1), pp. 1663-1704.

${ }^{87}$ SAN ISIDORO, op. cit. (n. 11), p. 106; SAN FRUCTUOSO, op. cit. (n. 11), p. 142-143.

${ }^{88}$ Regla Común, op. cit. (n. 37), p. 207.

${ }^{89}$ La Regla de San Benito, op. cit. (n. 59), p. 135-138; G. ARCHETTI, "Il vino non è per i monaci". Appunti sparsi sugli usi monastici antichi, in F. Monteleone e L. Lofoco (a cura di), "Dulcius nil est mihi veritate". Studi in onore di Pasquale Corsi, Foggia, 2015, p. 65-87; ID., op. cit. (n. 52) y ID., "De mensura potus". Il vino dei monaci nel medioevo, in G. Archetti (a cura di), La civiltà del vino. Fonti, temi e produzioni vitivinicole dal Medioevo al Novecento, Atti della VII Biennale di Franciacorta (Monticelli Brusati - Antica Fratta, 5-6 ottobre 2001), Brescia, 2003, p. 205-326.

${ }_{90}^{\circ}$ G. ARCHETTI, op. cit. (n. 67), p. 773 .

${ }^{91}$ La Regla de San Benito, op. cit. (n. 59), p. 136.

${ }_{92}^{2}$ Tantum manducabant ad sextam et seram ... quam ... manducarent ad nonam, quia solummodo illum cibum quem ad nonam manducabant, manducabant ad sextam et seram: HILDEMARO, Traditio super Regulam Sancti Benedicti, citado en Regula Sancti Benedicti Cassinensis comentata, en Patrologiae cursus completus. Series latina, ed. J.P Migne, LXVI, París, 1866, col. 615.
} 
la exclencia ascética, en un proceso que combina conceptos científicos con planteamientos espirituales, normas dietéticas con preceptos morales. Las renuncias alimenticias constituyen una práctica connanatural con la vida monástica, puesto que desempeñan un papel importante en el control de las pasiones. No sorprende, pues, que en muchas normativas claustrales, aparezcan estrechamente vinculadas a la castidad ${ }^{93}$. El monje debe ayunar no sólo para preservar la continencia, sino también para erradicar cualquier vicio. Las renuncias alimenticias y la plegaria constituyen los dos principales medios de que dispone el asceta para disciplinar el cuerpo, vencer las tentaciones y alcanzar la perfección moral ${ }^{94}$.

Benito de Nursia, aunque consideraba que la vida del asceta debería ser de una austeridad cuaresmal sistemática, restringió las mortificaciones alimentarias, consciente de que escaseaban las personas dispuestas a alcanzar tal nivel de exigencia, a la Cuaresma y a un amplio conjunto de días repartidos a lo largo del año. En los monasterios que se regían por la regla de Isidoro de Sevilla, los monjes ayunaban tres veces por semana, entre Pentecostés y el equinoccio de otoño, y todos los días laborables, desde el equinoccio de otoño hasta hasta Pascua, excepto por Navidad. Las restricciones alimentarias desaparecían completamente, en cambio, en las siete semanas comprendidas entre Pacua y Pentecostés, y en los ocho días subsiguientes a la Navidad, cuando la comunidad, en razón de la solemnidad de las citadas fiestas litúrgicas ${ }^{95}$, disfrutaba de sendos períodos de quieta laetitia. El calendario de las mortificaciones alimenticias, en la regla de Fructuoso de Braga, era algo más denso que el diseñado por el hispalense. Los ascetas, en Compludo, ayunaban varios días a la semana, entre Pentecostés y el equinoccio de otoño, excepto durante la "cuaresma" que precedía la festividad de los santos Justo y Pastor (9 de agosto), en que lo hacían diariamente; desde el equinocio de otoño hasta Pascua, las colaciones penitenciales únicas aparecían en el refectorio todos los días laborables ${ }^{96}$. Los ancianos y los niños, tanto en los monasterios de la Bética como en los de la Gallecia, estaban dispensados, sin embargo, de practicar los ayunos cotidianos ${ }^{97}$.

¿En qué consistía exactamente el ayuno monástico? En realidad coexistían diversos grados de mortificación alimentaria. El ordinario implicaba efectuar una única comida al dia, a la hora nona ${ }^{8}$. Fructuoso de Braga concibió una segunda modalidad de ayuno, algo más ligera, que permitía a los monjes comer a la hora sexta y les privaba de la cena; restringió su aplicación a las siete semanas comprendidas entre Pascua y Pentecostes ${ }^{99}$. Ambos tipos de mortificación no implicaban ningún cambio en la magnitud y composición de la dieta, puesto que los monjes recibían, en estas jornadas penitenciales, los mismos platos e idénticas cantidades de pan y e vino que en las ordinarias. El sufrimiento radicaba en la modificación del horario, en retrasar la abertura del refectorio de sexta a nona, en soportar tres horas más de hambre. El ayuno máximo incluía, además, reducciones cualitativas y cuantitativas de la colación única: Isidoro de Sevilla estableció que los monjes, durante la Cuaresma, deberían renunciar al vino y al aceite, y conformarse con una cena única de pan y agua ${ }^{100}$. En Compludo, durante la "cuaresma" que precedía a la festividad de los santos Justo y Pastor, el vino desaparecía de la mesa y, en la Cuaresma, también el aceite ${ }^{101}$. Las mortificaciones alimentarias, en las normas claustrales hispanas, eran, pues, más intensas que en la benedictina, cuyo autor soló había previsto dos modalidades, ninguna de las cuales implicaban menguas de las raciones. El ayuno normal consistía en concentrar todos los componentes de la dieta ordinaria en una comida única, a nona; el máximo, circunscrito a la Cuaresma, obligaba a los monjes a soportar varias horas más de hambre, al retrasar la abertura del refectorio a la puesta del sol ${ }^{102}$. Durante estas seis semanas de primavera, los miembros de la comunidad podían, además, privarse voluntariamente, con la autorización del abad, de una parte de la colación ${ }^{103}$.

Para evitar que el exceso de mortificación no deprimiese al monje, las restricciones alimenticias eran compensadas con algunas comidas extraordinarias, estratégicamente repartidas a lo largo del año. Isidoro de Sevilla, con una condescendencia sin paralelo, llega a autorizar el refuerzo de las verduras, en los días festivos, con pequeñas cantidades de carne $^{104}$. Fructuoso de Braga, algo menos generoso, establece que los monjes han de ser reconfortados con una medida de vino al atardecer, los sábados y los domingos, con tres platos calientes y otros tantos vasos de vino, en las grandes solemnidades del calendario litúrgico, y con la incorporación a la dieta de pescado de río o de mar, eventualmente ${ }^{105}$. La escasez de vino en la Galecia lo hacía bastante más deseable que en las riberas mediterráneas, de ahí que el Bracarense incrementase la pequeña medida cotidiana incluso en las vísperas de las jornadas de precepto.

La distribución cronológica de los suplementos de la dieta, en la Regla de Montecasino, está más en relación con el calendario "laboral” que con el litúrgico. Benito de Nursia sólo prevé explícitamente, como causa de alteración al alza del régimen cotidiano, el exceso de trabajo. La ración

93 SAN LEANDRO, op. cit. (n. 11), p. 56 y 65-66; SAN ISIDORO, op. cit. (n. 11), p. 105.

${ }_{94}$ G. ARCHETTI, op. cit. (n. 67), p. 768-769; ID., op. cit. (n. 1).

${ }_{95}$ SAN ISIDORO, op. cit. (n. 11), p. 108.

${ }^{96}$ SAN FRUCTUOSO, op. cit. (n. 11), p. 156.

${ }^{97}$ SAN ISIDORO, op. cit. (n. 11), p 108.

${ }_{98}^{8}$ Usque ad nonam quotidie ieiunando est: SAN FRUCTUOSO, op. cit. (n. 11), p. 156.

${ }_{99}$ A Pasqua usque Pentecosten reficiendum ad sextam est, et monofagia idem conservanda per diem: SAN FRUCTUOSO, op. cit. (n. 11$)$, p. 156.

${ }^{100}$ In obseruatione autem quadragessimae, sicut fieri solet post expletum ieiunium, pane solo uel aqua contenti omnes erunt; uino quoque et oleo astinebut (SAN ISIDORO, op. cit. (n.11), p. 106-107); Quando no solum a prandiis sed etiam a uino et ab oleo abstinentur (Ibidem, p. 108).

${ }^{101}$ SAN FRUCTUOSO, op. cit. (n. 11), p. 156.

${ }^{102}$ La Regla de San Benito, op. cit. (n. 59), p. 138-139.

${ }^{103}$ Ibidem, p. 150-151.

${ }^{104}$ Diebus uero sactis interdum cum oleribus leuissimarum carnium alimenta: SAN ISIDORO, op. cit. (n. 11), p. 105.

${ }^{105}$ SAN FRUCTUOSO, op. cit. (n. 11), p. 142-143. 
ordinaria de comida y bebida garantiza a los miembros de la comunidad el mínimo calórico necesario para desarrollar todas las tareas de la jornada; si efectúan labores más duras que las normales, el abad, para neutralizar el desgaste físico subsiguiente, puede concederles un suplemento alimenti$\mathrm{cio}^{106}$. Las reglas monásticas hispanas son bastante menos explícitas al respecto. San Isidoro no establece ninguna compensación nutricional para el sobreesfuerzo físico. El Bracarense, en cambio, autoriza a los monjes - como ya se ha expuesto - a comer carne de ave durante los viajes ${ }^{107}$ y faculta al abad para conceder, en las jornadas de ayuno cuaresmal, una medida de vino a los profesos que realicen trabajos agotadores ${ }^{108}$.

\subsection{Los servicios alimentarios y la comensalidad monástica}

La alimentación era tan importante para los ascetas que los redactores de las reglas confiaron a los profesos su preparación y su distribución. La tahona, el horno, la despensa, la cocina y el refectorio formaban parte de la clausura y, en consecuencia, los laicos no tenían acceso a ellos $^{109}$. Su funcionamiento era competencia exclusiva de la comunidad, que la asumía de acuerdo con un sistema de turnos semanales ${ }^{10}$. Los hebdomadarios iniciaban su tarea el domingo por la mañana, después de haber recibido, en la iglesia, la correspondiente bendición, y la finalizaban el sábado después vísperas, lavando los pies a los miembros de la comunidad ${ }^{11}$. Solamente los enfermos, los ancianos, los niños, el mayordomo y quienes desempeñaban cargos en el cenobio estaban exentos de participar en las tareas derivadas de la alimentación. Según los primeros teóricos del monacato, los monjes debían servirse mutuamente, para reforzar la cohesión interna y los vínculos de caridad en la familia claustral.

Las comidas colectivas tenían muchos aspectos positivos: favorecían la convivencia entre los monjes, facilitaban el control del comportamiento de cada comensal y dificultaban las desigualdades alimentarias. Los teóricos del primer cenobitismo occidental, conscientes de estas ventajas, convirtieron la mesa en un ámbito con un fuerte poder cohesionante y rodearon el hecho cotidiano de alimentarse de un ritual casi litúrgico. Todos los profesos, incluido el abad cuando no tenía huéspedes y presidía el almuerzo o la cena, compartían, tanto en los días normales como en los extraordinarios, un mismo régimen ${ }^{112}$. Esta opción obligó a las comunidades monásticas a someter las comidas a una rígida disciplina temporal $^{113}$, a crear un espacio específico, el refectorio, y a improvisar unos hábitos de mesa peculiares, muy diferentes a los desarrollados coetáneamente por los laicos.

A las horas convenidas, al toque de la campana, se cerraban las puertas del monasterio, para que ningún extraño "estorbara con su presencia”, y los monjes acudían todos juntos al refectorio ${ }^{114}$; donde se colocaban en sus respectivos sitios, distribuidos en mesas de diez comensales ${ }^{115}$, y esperaban, de pie y sin hablar, que entrase el abad. Una vez concluida la bendición de la mesa, los semaneros empezaban a servir los platos. Los monjes, al revés que los laicos, comían siempre en silencio riguroso, escuchando con atención al lector, a fin de recuperar simultáneamente las fuerzas físicas con los alimentos materiales y el vigor espiritual con los textos sagrados $^{116}$. Si en el transcurso de la refacción se producía una insuficiencia de comida o de bebida en una de las mesas, el monje que la presidía lo comunicaba por medio de un gesto a uno de los servidores, para que la solventase inmediamente ${ }^{117}$. El comedor conventual no constituía, pues, un ámbito de distensión y esparcimiento, sino un espacio de recogimiento y de silencio, donde los miembros de la comunidad se interrelacionaban de acuerdo con un rígido código de costumbres, cuya ruptura - como se verá más adelante - estaba severamente castigada. Los comensales no podían levantarse de la mesa ni salir de refectorio durante la comida ${ }^{118}$, tenían que aceptar sin murmuración ni queja los platos que se les servían ${ }^{119}$, pero podían renunciar a su ración de vino y de carne, puesto que la abstinencia era una opción positiva, que debía ser alentada ${ }^{120}$. Las refacciones se cerraban con una breve plegaria de acción de gracias, tras de la cual los monjes abandonaban rápidamente y en orden el refectorio, y los semaneros recogían la comida sobrante para distribuirla entre los pobres ${ }^{121}$. En la cocina y en el refectorio de los monasterios hispanos regía una ritualidad practicamente idéntica a la establecida por Benito de Nursia en Montecasino ${ }^{122}$.

\subsection{Las restricciones alimenticias}

Todos los maestros de ascetismo oriental y occidental consideraron las reducciones de la dieta como un buen mecanismo para corregir los deslices, faltas o delitos. Según

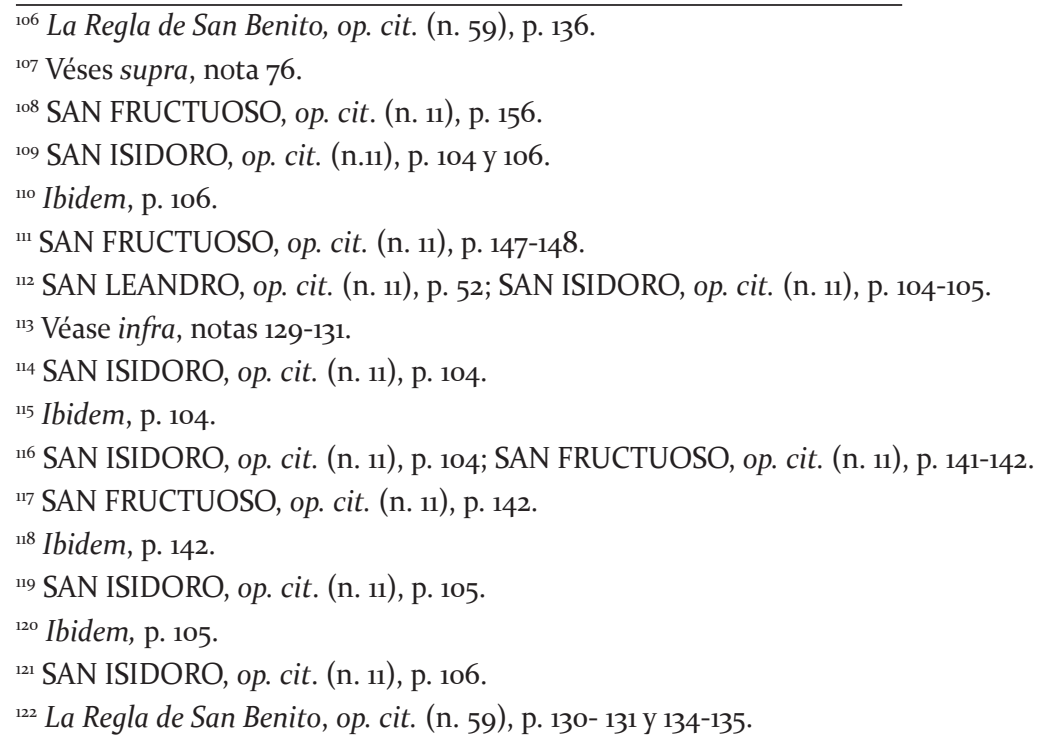


el codex poenalis inserto en las principales reglas ${ }^{123}$, toda sanción tiene una finalidad correctiva, no vindicativa, puesto que persigue exclusivamente erradicar los vicios, restablecer la salud del alma, educar al monje y encauzarlo por la vía de la perfección. Los monjes que se comportaban incorrectamente, dentro o fuera del monasterio, eran amonestados en privado por los ancianos encargados de su tutela moral, en las dos primeras ocasiones, y delante de toda la comunidad, en la tercera ${ }^{124}$. Las reglas hispanas, en este punto, conciden ampliamente con la norma benedictina ${ }^{125}$.

Mientras que los deslices se corregían mediante apercebimientos privados o públicos, las faltas implicaban ya sanciones más severas. En las comunidades monásticas, las penas, como en la sociedad civil, se tenían que ajustar siempre a la gravedad de la transgresión y a la edad y la capacidad de análisis del infractor ${ }^{126}$. La evaluación de estas circunstancias, en las comunidades benedictinas, competía exclusivamente al abad ${ }^{127}$; en las galaicas, intervenían también los ancianos ${ }^{128}$. Las normas claustrales hispanas conferían un interés especial a la corrección de la falta de puntualidad en el refectorio. La ausencia de la bendición de la mesa, en la Regla de Isidoro de Sevilla, implica una penitencia inespecífica o el retorno en ayunas al trabajo ${ }^{129}$. Frucutuoso de Braga, menos tolerante, castigaba la citada tardanza con la pérdida de la refacción ${ }^{130}$. Benito de Nursia había establecido que, después de las tres amonestaciones previstas, el reincidente, además de comer solo y más tarde que la comunidad, perdería la ración de vino ${ }^{131}$, testimonio indirecto del aprecio de que disfrutaba, a mediados del siglo VI, esta bebida entre los monjes italianos.

Se consideraban también faltas leves la ociosidad, la negligencia en el trabajo, el deterioro de una herramienta o de un libro, la falta de puntualidad a la plegaria, la risa en el coro, la charlatanería, la murmuración, la mentira, el descontrol de la lengua, el juramento reiterado, la insolencia contra un mayor, el intercambio epistolar y las entrevistas con parientes sin permiso del abad, la desobediencia, la soberbia, la relación con un excomulgado, el retiro transitorio a un lugar aislado, la ocultación de una polución nocturna y, en general, el menosprecio de la Regla y de los superiores ${ }^{132}$. Todas estas infracciones eran sancionadas con una excomunión menor, de dos o tres días de duración ${ }^{133}$. Esta penitencia consistía básicamente en la exclusión de la mesa común ${ }^{134} \mathrm{O}$ en la privación total de alimentos ${ }^{135}$. El monje que hubiese incurrido en tales faltas comía, en Montecasino y sus filiales, los mismos alimentos que la comunidad, pero más tarde y solo ${ }^{136}$; en los monasterios bercianos que se regían por la Regla de Fructuoso de Braga, contemplaba, además, de pie y con el gesto compungido, las refacciones comunitarias ${ }^{137}$.

La excomunión, incluida la menor, implicada, además de sanciones alimentarias, la desvinculación temporal de la comunidad. Tanto en Hispania como en Italia, la expulsión de la mesa, en el ámbito monástico, significaba, como entre las familias seculares, la segregación forzosa de un miembro, una pérdida transitoria de rango y una mengua de afecto por parte de los familiares. Comer solo, en un cenobio, constituía, más aún que en el entorno rural circundante, un signo de culpa y un instrumento de expiación. $\mathrm{Al}$ reo de este tipo de faltas no se le privaba, sin embargo, de participar con los restantes monjes en el oficio divino. La excomunión menor, entre los benedictinos, sólo impedía al sancionado asumir cualquier papel de "solista": no podía cantar salmos o antífonas ni recitar ningún tipo de lectura ${ }^{13^{8}}$. En Gallecia, en los confines noroccidentales del mundo latino, el profeso excomulgado, cuando la comunidad se reunía para rezar, no sólo no podía desempeñar ningún protagonismo, sino que, además, tenía que postrarse en tierra, despojarse del ceñidor y del manto, y pedir perdón a sus hermanos ${ }^{139}$.

Las faltas graves eran corregidas, entre los monjes, con penitencias bastante más duras y dolorosas que las mencionadas. Benito de Nursia diseñó con detalle las sanciones correspondientes a los pecados graves, que no definió ni enumeró: el culpable sería excluido de la mesa conventual y del oratorio, realizaría completamente solo los trabajos que se le asignaran; nadie, bajo pena de excomunión, podría hablar con él ni bendecir sus colaciones, cuya composición y horario establecería, en cada caso, el abad ${ }^{140}$. Para algunos hermeneutas contemporáneos ${ }^{141}$ los vicios peligrosos, en las

\footnotetext{
123 Ibidem, p. 117-124; SAN LEANDRO, op. cit. (n. 11), p. 68-70; SAN ISIDORO, op. cit. (n. 11), p. 112-117; SAN FRUCTUOSO, op. cit. (n. 11), p. 151-156; Regla Común, op. cit. (n. 37), p. 196-198 y 204-208.

${ }^{124}$ SAN ISIDORO, op. cit. (n. 11), p. 112. SAN FRUCTUOSO, op. cit. (n. 11), p. 154.

${ }^{125}$ La Regla de San Benito, op. cit. (n. 59), p. 117-118.

${ }^{126}$ SAN ISIDORO, op. cit. (n. 11), p. 116; SAN FRUCTUOSO, op. cit. (n. 11), p. 153; La Regla de San Benito, op. cit. (n. 59 ), p. 118 y 124.

${ }^{127}$ La Regla de San Benito, op. cit. (n. 59), p. 118.

${ }^{128}$ SAN FRUCTUOSO, op. cit. (n. 11), p. 153.

${ }^{129}$ SAN ISIDORO, op. cit. (n. 11), p. 104.

${ }^{130}$ SAN FRUCTUOSO, op. cit. (n. 11), p. 157.

${ }^{131}$ Si denuo non emendaverit, non permittatur ad mensae communis participationem, sed sequestratus a consortio omnium, reficiat solus, sublata ei portione sua de vino: La Regla de San Benito, op. cit (n. 59), p. 142; G. ARCHETTI, op. cit. (n. 89).

${ }^{132}$ SAN ISIDORO, op. cit. (n. 11), p. 114-115.

${ }^{133}$ SAN ISIDORO, op. cit. (n. 11), p. 115; SAN FRUCTUOSO, op. cit. (n. 11), p. 153.

${ }^{134}$ La Regla de San Benito, op. cit. (n. 59), p. 118; SAN FRUCTUOSO, op. cit. (n. 11), p. 152.

${ }^{135}$ Si excommunicatio biduana fuerit excommunicato, nihil illi alimenti praebendum est: SAN ISIDORO, op. cit. (n. 11), p. 117.

${ }^{136}$ La Regla de San Benito, op. cit. (n. 59), p. 118.

${ }^{137}$ SAN FRUCTUOSO, op. cit. (n. 11), p. 152.

${ }^{138}$ La Regla de San Benito, op. cit. (n. 59), p. 118.

${ }^{139}$ SAN FRUCTUOSO, op. cit. (n. 11), p. 152.

${ }^{140}$ La Regla de San Benito, op. cit. (n. 59), p. 119.

${ }^{141}$ Como García M. Colombás, en La Regla de San Benito, op. cit. (n. 59), p. 401.
} 
abadías benedictinas, fueron castigados incialmente con un fuerte aislamiento, más moral que físico; quienes cometían una falta grave eran completamente ignorados por los hermanos y no podían compartir con ellos las plegarias, las comidas ni los trabajos. Para el abad de Montecasino, las penas corporales - los azotes y los ayunos prolongados - no eran sino sucedáneos de la excomunión y, en consecuencia, quedaban reservados para los incapaces de calibrar la gravedad de sus faltas, los niños y los adolescentes, y para los adultos reincidentes, duros de mente y de corazón, a quienes no afectaban las sanciones espirituales ${ }^{142}$.

Los dos grandes reformadores hispanos, menos optimistas respecto a la rectitud de discernimiento de los futuros abades que el padre del monacato italiano, inventariaron con cuidado, en los respectivos códigos, las faltas graves. Según Isidoro de Sevilla, tanto la embriaguez, el trato familiar con mujeres, la ira, el orgullo, la vanidad, la calumnia, la envidia, la maledicencia, la mentira, el hurto, el manejo de dinero, la posesión de cosas superfluas y el perjurio, como sembrar discordias, no devolver los bienes recibidos o vanagloriarse de los aportados, causar un perjuicio importante a la comunidad, provocar enfrentamientos internos, denigrar a un inocente, despreciar a un anciano, injuriar a un hermano, negarle el perdón, cultivar el rencor, comer furtivamente, fingir una enfermedad para no trabajar, decir chocarrerías ante un niño o besarle, acostarse con otro monje y ausentarse del monasterio media jornada sin permiso del abad consituyen vicios muy peligrosos para un asceta y han de ser corregidos, por lo tanto, con una excomunión larga y con azotes ${ }^{143}$. El excomulgado, con el fin de evidenciar su vileza, será confinado a unas dependencias especiales del monasterio, vetadas a los restantes monjes; dormirá, excepto durante el invierno, en el suelo, encima de una estera, y calzará sandalias de esparto ${ }^{144}$.

Fructuoso de Braga, más gradualista que el Hispalense, distingue diversas categorías de faltas graves y establece una sanción específica para cada una de ellas. El primer nivel corresponde a los monjes vagabundos, giróvagos, que deben ser castigados con dos meses de excomunión y con una dieta hipocalórica, integrada exclusivamente por una pequeña cantidad de pan y agua ${ }^{145}$. El Bracarense coloca en la segunda cota de gravedad a los ascetas que hubiesen quebrantado la abstinencia de la carne, para los que establece un correctivo de seis meses de arresto $^{146}$. Vienen a continuación los rein- cidentes de faltas leves, la pena consistirá, en este caso, en azotes, una larga reclusión y un ayuno fuerte, que reducirá la colación cotidiana a una exigua ración de pan y agua ${ }^{147}$. El tercer grado concierne tanto a los mentirosos, violentos, ladrones y perjuros reincidentes, como a los ebriosos y a aquellos profesos que escriban o reciban cartas sin permiso del abad o del prior; estos vicios serán enmendados con una flagelación prolongada, una excomunión de tres meses, el aislamiento en una celda especial y una rigurosa monofagia, el sancionado sólo ingerirá diariamente, a vísperas, seis onzas de pan de cebada y una escasa cantidad de agua ${ }^{14^{8}}$.

El pecado más grave que puede cometer un monje es, sin embargo, la pederastia, el comportamiento más incompatible con la vida cenobítica y el ascetismo. La pena prevista para este delito somete al culpable a una combinación de vejaciones, castigos corporales y pérdidas de derechos. El corruptor convicto de un menor será azotado en público, se le afeitará la cabeza, se le expondrá al oprobio y tendrá que soportar los salivazos en la cara de todos los miembros de la comunidad; se le encerrará, después, seis meses en la prisión conventual, donde, inmovilizado permenentemente con cadenas de hierro, sólo recibirá tres veces por semana, al atardecer, una pequeña ración de pan de cebada y de agua. Una vez concluida esta fase de la larga sanción, se le someterá, durante seis meses, al control de un anciano virtuoso y, confinado en una celda especial, se dedicará al trabajo y a la oración incesantes. Cuando, después de vigilias, lágrimas, humillaciones y pruebas reiteradas e inequívocas de arrepentimiento, obtenga el perdón de la comunidad, se moverá siempre por el monasterio bajo la vigilancia ininterrumpida de dos monjes y no podrá hablar nunca más con los niños ni los adolescentes ${ }^{149}$.

Todavía más severa se muestra la Regla Común con las faltas graves de los ascetas. Los anónimos autores del segundo código galaico, conscientes del importante papel que los rebaños desempeñaban en la economía de sus respectivos monasterios ${ }^{150}$, no dudan en sancionar a los monjes pastores que, por incuria o desidia, hubiesen perdido alguno de los animales que la comunidad les confió con la penitencia correspondiente a los pecados graves o con una flagelación, si eran adolescentes ${ }^{151}$. El cenobita sorprendido, en un monasterio dúplice, hablando a solas con una profesa será corregido, a fin de erradicar cualquier circunstancia que pudiese incitar a la lujuria, con cien $\operatorname{azotes}^{152}$. Los re-

\footnotetext{
${ }_{142}$ La Regla de San Benito, op. cit. (n. 59), p. 122 y 124.

${ }^{143}$ SAN ISIDORO, op. cit. (n. 11), p. 115-116.

${ }^{144}$ Ibidem, p. 116-117.

${ }^{145}$ SAN FRUCTUOSO, op. cit. (n. 11), p. 161-162.

${ }^{146}$ Quod si quis monacus uiolauerit et contra sanctionem regulae usumque ueternum uesci carne praesumserit, sex mensium spatio retrusioni paenintentiae subiacebit: SAN FRUCTUOSO, op. cit. (n. 11), p. 142.

${ }_{147}$ Plagis emendetur, instantius, reclusionisque diutinae coartetur angustiis. Breuissimi panis et aquae esu sustentandus donec se spondeat a uitio recessurum: SAN FRUCTUOSO, op. cit. (n. 11), p. 153. Para una comparación con un ambiente reformador cf. G. ARCHETTI, "Solum in pane et aqua abstinere". L'alimentazione a Fonte Avellana al tempo di Pier Damiani, in N. D’Acunto (a cura di), Fonte Avellana nel secolo di Pier Damiani, Atti del XXIX Convegno del Centro Studi Avellaniti (Fonte Avellana, 29-31 agosto 2007), San Pietro in Cariano (Vr), 2008, p. 179-211.

${ }^{14^{8}}$ De uespere in uesperi sex hordeacei panis unciis et aquae mensura paruula sustentetur: SAN FRUCTUOSO, op. cit. (n. 11$)$, p. 154.

149 SAN FRUCTUOSO, op. cit. (n. 11), p. 154-155. Para la educación de los adolescentes cf. G. ARCHETTI, L'educazione dei "pueri oblati”: reclutamento, formazione e finalità, in M.E. Varela-Rodríguez (ed.), La historiografia medieval davant la crisi. La historiografía medieval ante la crisis, Girona, 2015 (Estudis de Cultura Escrita i Visual, 3), p. 67-124; ID., "Sub virga magistri". Custodia e disciplina nell'educazione carolingia dei pueri oblati, «Studi medievali», LVII, 2, 2016, p. 527-582.

${ }^{150}$ Véase supra, nota 37.

${ }^{151}$ Regla Común, op. cit. (n. 37), p. 187.

${ }^{152}$ Ibidem, p. 199.
} 
incidentes, después de flagelados, serán encarcelados y, si no enmiendan, deberán abandonar el cenobio ${ }^{153}$. El afán ascético de muchos monjes bercianos debía de ser escaso; bastantes profesos habrían buscado detrás de los muros conventuales más refugio y sustento que un nuevo modelo de vida. El pesimismo "antropológico" de los abades de la congregación ha quedado claramente reflejado en el capítulo en el que establecen el largo y duro proceso de reconciliación de un excomulgado. El asceta que incurra en una falta grave será aislado de los hermanos, que no podrán acercársele para consolarlo, y confinado a una celda obscura, donde sólo recibirá la visita de los monjes enviados expresamente por el abad para comprobar su estado físico y moral; vestirá una capa vieja y rota y será sometido a un régimen alimenticio especial, mínimo, exclusivamente de subsistencia. La dieta de un excomulgado, menos consistente incluso que la penitencial de Cuaresma, no constará más que de medio pan y de una pequeña cantidad de agua; dos alimentos que, cada atardecer, después de vísperas, recibirá, exorcizados, no bendecidos, por el abad ${ }^{154}$.

Cuando la vigencia de la excomunión no superara los dos o tres días, el abad, en el momento que considere oportuno, enviará un monje de su confianza al condenado para que le insulte, recriminándole haber ingresado en el monasterio no para alcanzar la perfección espiritual sino para provocar desórdenes. El excomulgado, después de soportar con resignación y humildad, sin murmurar, tres sesiones sucesivas de ofensas, será conducido ante la asamblea conventual, donde el abad, para comprobar la sinceridad de su arrepentimiento, le repetirá las afrentas. Si superaba esta nueva prueba, se le permitiría ingresar en la iglesia, para, postrado en tierra, implorar el perdón del superior. El pecador, después de escuchar atentamente las amonestaciones del abad y de recibir su ósculo, podrá considerarse renconciliado y reocupará su lugar en el coro. El excomulgado que, a la primera tanda de improperios, se mostrase quejoso o defendiese obstinadamente su opinión, verá incrementada en tres días más su sanción. Si mantuviese esta actitud contestaria durante tres interrogatorios sucesivos, será recluido en la cárcel conventual, donde permanecerá hasta que no entre en razón. Aquellos excomulgados que, después de un largo encierro, persistiesen en su contumacia, tendrán que a dejar el hábito y a abandonar el cenobio, puesto que su carácter se ha revelado incompatible con la disciplina ascética ${ }^{155}$.

Si todo este complejo proceso se ponía en funcionamiento para una excomunión inicial de dos o tres días ¿qué se le exigiría a un reo de una falta más grave antes reintegrarle a la comunidad? Una lectura atenta del conjunto de la norma y la información complementaria aportada por el modelo en que se inspira, la Regla de Fructuoso de Braga, permiten formarse una idea bastante aproximada. La dureza de los códigos penales galaicos, muy superior a la de los béticos, sería imputable más al tipo de monje al que estaban destinados que a un modelo de ascetismo más exigente y riguroso.
En los monasterios de Compludo y de Dumio y en sus respectivas filiales, como reconocen expresamente las Reglas del Bracarense ${ }^{156}$ y Común ${ }^{157}$, ingresaban como novicios hombres de muy diversa extracción social, entre los que no faltaban los veteranos de los ejércitos, los marginados y los delicuentes. Sólo con una disciplina firme podían los abades mantener el orden en comunidades cultural y moralmente tan heterogéneas

¿Cómo podía resistir un hombre adulto unos regímenes alimentarios tan estrechos durante un período prolongado? Sólo un sedentarismo total permitiría a los excomulgados sobrevivir seis meses con tres raciones semanales de pan negro y agua. Con un nivel de calorías tan bajo, no se debía de poder desarrollar casi ninguna actividad física ni intelectual; sus principales secuelas consistirían en una modificación profunda de hábitos, en el olvido de casi todos los proyectos y en el ahorro de energías, para concentrar las pocas disponibles en el mantenimiento de las estrictas funciones biológicas. Los redactores de las normas galaicas, para erradicar los delitos graves, especialmente la pederastia, establecieron unas penas de una severidad disuasoria para los posibles infractores, a fin de no tenerlas que aplicar. Las sanciones estaban incluidas, sin embargo, en el codex poenalis de la reglas y, por tanto, eran conocidas por todos los miembros de la comunidad, que las escuchaban periódicamente. Si se demostraba feacientemente que un monjes había cometido uno de estos crímenes, se le tendría que aplicar, por lo tanto, el castigo previsto. Es de suponer que si el reo no podía soportarlo, el abad no permitiría que muriera de inanición o víctima de la locura, y suspendería, con el asesoramiento de los ancianos, su aplicación, aduciendo que su finaldidad era correctiva, no vindicativa.

La sustracción de alimentos constituía, pues, una sanción muy frecuente y eficaz entre los monjes, un colectivo sometido sistemáticamente a un régimen frugal y escaso, pobre en proteínas y grasas. Todos los maestros de ascetismo la utilizan profusamente, con la esperanza de que el pecador, "macerado" en ayunos frecuentes ${ }^{158}$, físicamente debilitado, ablandara el carácter, rectificara la conducta y se sometiera a una firme disciplina moral, sin la cual la vida en comunidad y el ascetismo serían imposibles

\section{CONCLUSIONES}

Los moralistas cristianos antiguos, apoyándose en la dietética clásica, consideraron que la gula era el primero de los vicios, que el gusto por la comida constituía el incio de un proceso de supeditación del espíritu al cuerpo, que la buena mesa conducía a la perdición. En los siglos VI y VII, los compiladores de los usos monásticos, que conocían bien tanto las Escrituras y la Patrística como la cultura clásica, concedieron una atención preferente a la alimentación. La primera dietética monástica perseguía cuatro objetivos básicos: dominar las pasiones de la gula y de la lujuria,

\footnotetext{
153 Ibidem, p. 199-220.

${ }^{154}$ In solo pane et aqua, ut in uespera, post cenam fratrum, medium accipiat paximatium et non ad sacietatem aquam. Et hoc ab abbate exsufflatum non sanctificatum: Ibidem, p. 196.

155 Ibidem, p. 196-198.

${ }^{156}$ SAN FRUCTUOSO, op. cit (n. 11), p. 153-155 y 159-162.

157 Regla Común, op. cit. (n. 37), p. 178-179, 185 y 204-208.

${ }_{158}^{8}$ Saepius suspendatur a cibo et biduanis siue triduanis maceretur ieiuniis: SAN FRUCUTUOSO, op. cit. (n. 11$)$, p. 153.
} 
estrechamente interconectadas, ser consecuente con la pobreza inherente a la vida ascética, favorecer la plegaria y, en general, toda las actividades del espíritu, y no comprometer la salud del monje.

Las disposiciones alimentarias de las cuatro reglas hispanas analizadas presentan muchos más paralelismos que divergencias y coinciden ampliamente con la normativa benedictina inicial. La dieta ordinaria del monje era exclusivamente vegetariana y estaba integrada por legumbres, verduras, pan, vino, aceite, sal y vinagre. La fe en el valor expiatorio de las restricciones alimenticias era otra de las ideas ampliamente compartida por los maestros de espiritualidad. La sustracción de calorías y de proteínas, en la medida en que reducía las energías físicas y psicológicas, apagaba las pasiones y facilitaba el reencauzamiento de los pecadores por la senda de la perfección espiritual.

Las faltas leves eran corregidas con la expulsión de la mesa conventual, el retraso de la colación, la privación de la ración de vino o la pérdida de la refección. Estas restricciones puntuales no impedían al sancionado participar en el oficio divino ni le dispensaban de sus tareas ordinarias.

El alcance y la duración de las sustracciones alimenticias se incrementaban a medida que se elevaba la gravedad del delito a enmendar. Los vicios graves eran erradicados con largos ayunos, durante los cuales la dieta se reducía a una exigua cantidad de pan y agua. Los reos de pederastia - el pecado más incompatible con la vida cenobítica y el ascetismo - sólo recibían, durante seis meses, un pequeño pan de cebada y un vaso de agua tres veces a la semana. En este último caso, los excomulgados, como consecuencia de un régimen hipocalórico, no podrían desarrollar casi ninguna actividad física ni intelectual; encerrados en una celda aislada o en la cárcel conventual, en sedentarismo permanente, concentrarían sus escasas fuerzas en el mantenimiento de las estrictas funciones biológicas. Los redactores de las normativas galaicas, para erradicar de las comunidades el vicio que consideraban más grave, establecieron una pena de una magnitud tal que la hacía difícilmente aplicable. El objetivo de la misma consistiría en prevenir la depravación, en disuadir a posibles delincuentes. La sanción, sin embargo, aparecía inserta en la norma claustral, que se leía diariamente, por capítulos, en voz alta a los monjes. Si, a pesar de todo, el delito se producía, el abad, después de cerciorarse de que se había cometido, tendría que someter el reo a la dura sanción prevista. Es de suponer que, en el caso en que éste no pudiera resistir un período de seis meses con una dieta tan exigua y en unas condiciones ambientales tan adversas, el abad, con el asesoramiento de los ancianos, suspendería su aplicación, para evitar su muerte por inanición o el descontrol permanente de sus facultades psicológicas, alegando que la pena era correctiva, no vindicativa. 